\title{
AVALIAÇÃO DE MÉTODOS DE INTERPOLAÇÃO PARA ESPACIALIZAÇÃO DE DADOS DE TEMPERATURA DO AR NA BACIA DO RIO PARANAÍBA - BRASIL
}

\author{
MARTINS, Alécio Perini - alecioperini@ufg.br \\ Universidade Federal de Goiás - Regional Jataí / UFG \\ ALVES, Wellmo dos Santos - wellmo.alves@ifgoiano.edu.br \\ Instituto Federal Goiano - Campus Rio Verde / IFG \\ DAMASCENO, Carlos Eduardo - eduardo.geo@outlook.com.br \\ Universidade Federal de Goiás - Regional Jataí / UFG
}

\begin{abstract}
RESUMO: Nas últimas décadas, a Climatologia Geográfica tem incorporado ferramentas de geotecnologias em suas pesquisas como os métodos de interpolação e espacialização de dados, permitindo um excelente ganho de tempo e qualidade no tratamento e análise da informação. Estes métodos se dividem principalmente em determinísticos e geoestatísticos e possibilitam a análise espacial de elementos como temperatura e precipitação, mesmo em áreas com baixa densidade de estações de monitoramento. Neste artigo, pretende-se comparar e analisar a eficiência de seis métodos, três determinísticos e três geoestatísticos, para interpolação e espacialização de dados de temperatura do ar na Bacia do Rio Paranaíba. Para o estudo, selecionou-se 34 estações automáticas do INMET (Instituto Nacional de Meteorologia) na área da bacia e entorno considerando informações do mês de agosto de 2018 e as variáveis temperatura do ar média mensal e temperatura instantânea às 09:00h, 15:00h e 21:00h (horário de Brasília) no dia 01 de agosto de 2018. Outras variáveis como altitude e direção de vertentes foram obtidas a partir do processamento de imagens de radar SRTM/NASA na resolução de $30 \mathrm{~m}$. Foram utilizadas ferramentas de Geotecnologias, especialmente as extensões 3D Analyst e Geoestatistical Analyst do Software ArcGIS 10.1®, licenciado para o Laboratório de Geoinformação da UFG - Regional Jataí. Observou-se que em áreas com baixa densidade de estações os métodos determinísticos apresentam um menor percentual de erro médio final, embora os métodos geoestatísticos forneçam dados mais exatos e com maior correlação entre os dados registrados e os dados estimados, permitindo, inclusive, a inserção de covariáveis como a altitude (Cokrigagem) que reduz o erro médio e aumenta a correlação entre dados registrados e estimados. Em geral, as estações apresentaram erro médio de até $1{ }^{\circ} \mathrm{C}$, para mais ou para menos, chegando a valores superiores a $4{ }^{\circ} \mathrm{C}$ em estações utilizadas na parte externa da bacia para realizar a interpolação.
\end{abstract}

Palavras-chave: Isotermas; Geoestatística; Análise espacial; Clima local.

EVALUATION OF INTERPOLATION METHODS FOR SPATIALIZATION OF AIR TEMPERATURE IN THE PARANAÍBA RIVER BASIN - BRAZIL.

ABSTRACT: In the last decades, Geographical Climatology has incorporated geotechnology tools in its researches such as interpolation methods and data spatialization, allowing an excellent gain in time and quality in the treatment and analysis of information. These methods divide into deterministic and geostatistical and enable the spatial analysis of elements such as temperature and precipitation even in areas with low density of monitoring stations. In this paper, we intend to compare and analyze the efficiency of six methods, three deterministic and three geostatistical methods, for interpolation and spatialization of air temperature data in the Paranaíba River Basin. For the study, 34 INMET (National Institute of Meteorology) automatic stations selected in the basin and surrounding area considering information from August 2018 and the variables average monthly air temperature and instantaneous temperature at 09:00, 15:00 and 21:00 (Brasília time) on August 1, 2018. Other variables such as altimetry and 
direction of slopes obtained from the SRTM / NASA radar image processing at a resolution of $30 \mathrm{~m}$. Geotechnology tools were used, especially the 3D Analyst and Geoestatistical Analyst extensions of the ArcGIS 10.1® Software, licensed to the UFG Geoinformation Laboratory - Jataí Regional. It was observed that in areas with low station density the deterministic methods present a lower percentage of final mean error. The geostatistical methods provide more accurate data and with a higher correlation between the recorded data and the estimated data, allowing even the insertion of covariables such as altimetry (Cokriging) that reduces the mean error and increases the correlation between recorded and estimated data. In general, the stations presented an average error of up to $1{ }^{\circ} \mathrm{C}$, more or less, reaching values higher than $4^{\circ} \mathrm{C}$ in stations used in the outside of the basin to perform the interpolation.

Keywords: Isotherms; Geostatistics; Spatial analysis; Local climate

EVALUACIÓN DE MÉTODOS DE INTERPOLACIÓN PARA LA ESPACIALIZACIÓN DE DATOS DE TEMPERATURA DEL AIRE EN LA BACIA DEL RIO PARANAÍBA - BRASIL.

RESUMEN: En las últimas décadas, la Climatología Geográfica ha incorporado herramientas de geotecnología en sus investigaciones como los métodos de interpolación y espacialización de datos, permitiendo una excelente ganancia de tiempo y calidad en el tratamiento y análisis de la información. Estos métodos se dividen principalmente en deterministas y geoestadísticos y posibilitan el análisis espacial de elementos como temperatura y precipitación incluso en áreas con baja densidad de estaciones de monitoreo. En este artículo, se pretende comparar y analizar la eficiencia de seis métodos, tres deterministas y tres geoestadísticos, para interpolación y espacialización de datos de temperatura del aire en la Cuenca del Río Paranaíba. Para el estudio, se seleccionaron 34 estaciones automáticas del INMET (Instituto Nacional de Meteorología) en el área de la cuenca y entorno considerando informaciones del mes de agosto de 2018 y las variables temperatura del aire promedio mensual, y temperatura instantánea a las 09:00h, 15:00 y 21:00h (horario de Brasilia) el día 01 de agosto de 2018. Otras variables como altitud y dirección de vertientes fueron obtenidas a partir del procesamiento de imágenes de radar SRTM / NASA en la resolución de $30 \mathrm{~m}$. Se utilizaron herramientas de Geotecnologías, especialmente las extensiones 3D Analyst y Geoestatistical Analyst del Software ArcGIS $10.1 \AA$, licenciado para el Laboratorio de Geoinformación de la UFG - Regional Jataí. Se observó que en áreas con baja densidad de estaciones los métodos deterministas presentan un menor porcentaje de error medio final, aunque los métodos geoestadísticos proporcionan datos más exactos y con mayor correlación entre los datos registrados y los datos estimados, permitiendo incluso la inserción de covariables como la altitud (Co-Krigagem) que reduce el error medio y aumenta la correlación entre datos registrados y estimados. En general, las estaciones presentaron error promedio de hasta $1^{\circ} \mathrm{C}$, para más o para menos, llegando a valores superiores a $4{ }^{\circ} \mathrm{C}$ en estaciones utilizadas en la parte externa de la cuenca para realizar la interpolación.

Palabras Clave: Isotermas; Geoestadística; Análisis espacial; Clima local.

\section{INTRODUÇÃO}

O monitoramento de diferentes elementos do clima tem se tornado indispensável para avaliar o comportamento destes na dinâmica climática, bem como subsidiar atividades de planejamento, avaliação e gestão dos recursos ambientais. A corrida espacial e a descoberta e aperfeiçoamento de novas tecnologias têm difundido o uso de ferramentas e técnicas de geoprocessamento e sensoriamento remoto que, por sua vez, provocam ganhos em tempo e disponibilização de informações.

Em climatologia, estas ferramentas se tornam indispensáveis a partir do momento em que possibilitam a aplicação de modelos matemáticos que permitem o estudo de extensas áreas com baixa cobertura de estações de 
coleta de dados em campo, como estações meteorológicas, por exemplo. A modelagem permite "simular os processos e predizer os efeitos resultantes nas mudanças e nas interações internas" (CHRISTOFOLETTI, 2000, P.15), sendo indispensável para analisar a distribuição espacial e sazonal de elementos do clima, bem como suas variações no decorrer do tempo e impactos sobre o ambiente e a sociedade. Entre as aplicações das Geotecnologias em Climatologia, uma das técnicas mais utilizadas é a interpolação para espacialização de dados climáticos como a precipitação pluvial, temperatura do ar, pressão atmosférica, entre outras.

Autores como Goovaerts (2000), Carvalho e Assad (2005), Melo e Silva (2009), Viola et al (2010), Silva et al (2011), Carvalho, Assad e Pinto (2012), Gardiman Júnior et al (2012), Cunha et al (2013), Franco e Uda (2015), entre outros, destacam a importância do uso de interpoladores para a espacialização de dados climatológicos, visto que as informações coletadas são pontuais e acabam não permitindo a visualização das tendências de distribuição espacial destas variáveis em áreas sem estações de monitoramento. Os autores destacam também que existem diferentes métodos de interpolação, a maioria processada por ferramentas automáticas em softwares de geoprocessamento, que podem apresentar-se mais adequados ou não dependendo das características físicas da área estudada, densidade de cobertura por estações de monitoramento e qualidade dos dados coletados nestas estações, entre outros fatores.

Existem dois métodos de interpolação mais utilizados para espacialização de dados climatológicos: o método determinístico, sendo o inverso do quadrado da distância (IDW) o mais conhecido e o método geoestatístico, representado principalmente pela Krigagem. Yamamoto e Landim (2013), destacam que o sistema de krigagem baseia-se na ideia de que quanto maior a covariância entre uma amostra e o local que está sendo estimado, mais essa amostra deve contribuir com a estimativa. Dessa forma, considera-se que é um método mais significativo para áreas com maior cobertura de pontos de monitoramento, apresentando estimativas mais confiáveis.

A krigagem pode ser usada, como algoritmo estimador, para: a) A previsão do valor pontual de uma variável regionalizada em um determinado local dentro do campo geométrico; é um processo de interpolação exato que leva em consideração os valores observados na vizinhança próxima, o qual pode ser a base para a cartografia automática por computador quando se dispõe de valores de uma variável regionalizada distribuídos em uma determinada área [...]; (YAMAMOTO e LANDIM, 2013, p. 63)

A Cokrigagem, extensão multivariada da krigagem, é utilizada quando a variável de interesse da krigagem (no caso a temperatura) pode ser subestimada ou superestimada em relação a outras covariáveis, como o relevo por exemplo (CUNHA et al, 2013, p.1180). Dessa forma, ao inserir a variável altitude no processo de interpolação é possível refinar os resultados, reduzindo o erro. Para áreas montanhosas ou com relevo acidentado, o uso deste método é fundamental. Cunha et al (2013), ao utilizar este interpolador para o estado do Espírito Santo, inseriram uma variável relativa à distância do mar e outra relativa à altitude, com resultados significativos para esta última variável. 
Salienta-se que, antes de utilizar o método, é preciso observar se realmente existe correlação entre as variáveis utilizadas.

Uma de suas mais frequentes aplicações ocorre quando a amostragem de uma variável primária é insuficiente e o objetivo é melhorar a sua estimativa, o que é feito utilizando-se a correlação da variável primária com variáveis secundárias mais densamente amostradas. Ela também é utilizada quando a variável primária exibe uma baixa autocorrelação espacial e as variáveis secundárias apresentam uma alta continuidade. (YAMAMOTO e LANDIM, 2013, p. 123)

Quando processadas no software ArcGIS $10.1 \AA$, tanto krigagem quanto a cokrigagem podem fornecer dados exatos, dependendo do modelo de erro de medição. Por se tratar de um processo estocástico estacionário, é um método bastante flexível e permite o cálculo automático de erros por correlação cruzada, incluindo previsão de erros padrão, probabilidade e quartil (ESRI, 2012).

Já o IDW é um método puramente geométrico, onde o peso entre as amostras diminui à medida em que essas amostras se distanciam. Enquanto essas distâncias são euclidianas no IDW, na krigagem são baseadas na análise variográfica, que consideram o relacionamento entre os pontos conhecidos e os pontos estimados, fornecendo informações mais detalhadas sobre o agrupamento (YAMAMOTO e LANDIM, 2013). Apesar de ser uma boa maneira para uma primeira análise sobre a área, não apresenta avaliação dos erros de previsão, além de produzir círculos com valores superestimados ou subestimados próximos às estações utilizadas para interpolação.

Outro método determinístico bastante utilizado é o Spline (Radial Basis Function, no ArcGIS), definido por ESRI (2012) como interpoladores determinísticos moderadamente rápidos, exatos e mais flexíveis que o IDW por permitirem a inserção de outros parâmetros. Apesar de também não apresentar avaliação automática de erros, proporciona superfícies de previsão comparáveis à exatidão oferecida pela krigagem por não fazer suposição sobre os dados.

Neste estudo, objetivou-se realizar uma comparação entre 6 métodos de espacialização de dados de precipitação, analisando qual se mostra mais adequado para áreas com características semelhantes às da Bacia do Rio Paranaíba. De forma mais específica, objetivou-se comparar a eficiência de métodos determinísticos e geoestatísticos para áreas com baixa densidade de monitoramento em campo e avaliar os erros apresentados por cada um destes métodos na estimativa de temperatura instantânea e da temperatura média.

\section{MATERIAL E MÉTODOS}

\section{ÁREA DE ESTUDO}

A área escolhida para o desenvolvimento da pesquisa é representada pela Bacia Hidrográfica do Rio Paranaíba (Figura 1), um dos principais afluentes da Bacia do Rio Paraná, com área aproximada de 230.000 km².

A bacia do rio Paranaíba é a segunda maior unidade da Região Hidrográfica do Paraná, ocupando $25,4 \%$ de sua área (...). Posicionada na região central do Brasil, ocupa cerca de $2,6 \%$ do território nacional e inclui os estados de Goiás (63,3\%), Mato Grosso do Sul $(3,4 \%)$ e Minas Gerais $(31,7 \%)$, além do Distrito Federal (1,6\%). A bacia possui 197 municípios, além do Distrito 
Federal. Destes, 28 sedes municipais se encontram fora dos limites da bacia (ANA, 2013)

Conforme o Plano de Recursos Hídricos da Bacia do Rio Paranaíba (ANA, 2013), segundo a classificação climática de Köppen, o clima se caracteriza como Aw, tropical quente em todas as estações do ano, com temperatura média mensal superior a $18{ }^{\circ} \mathrm{C}$ com inverno seco.

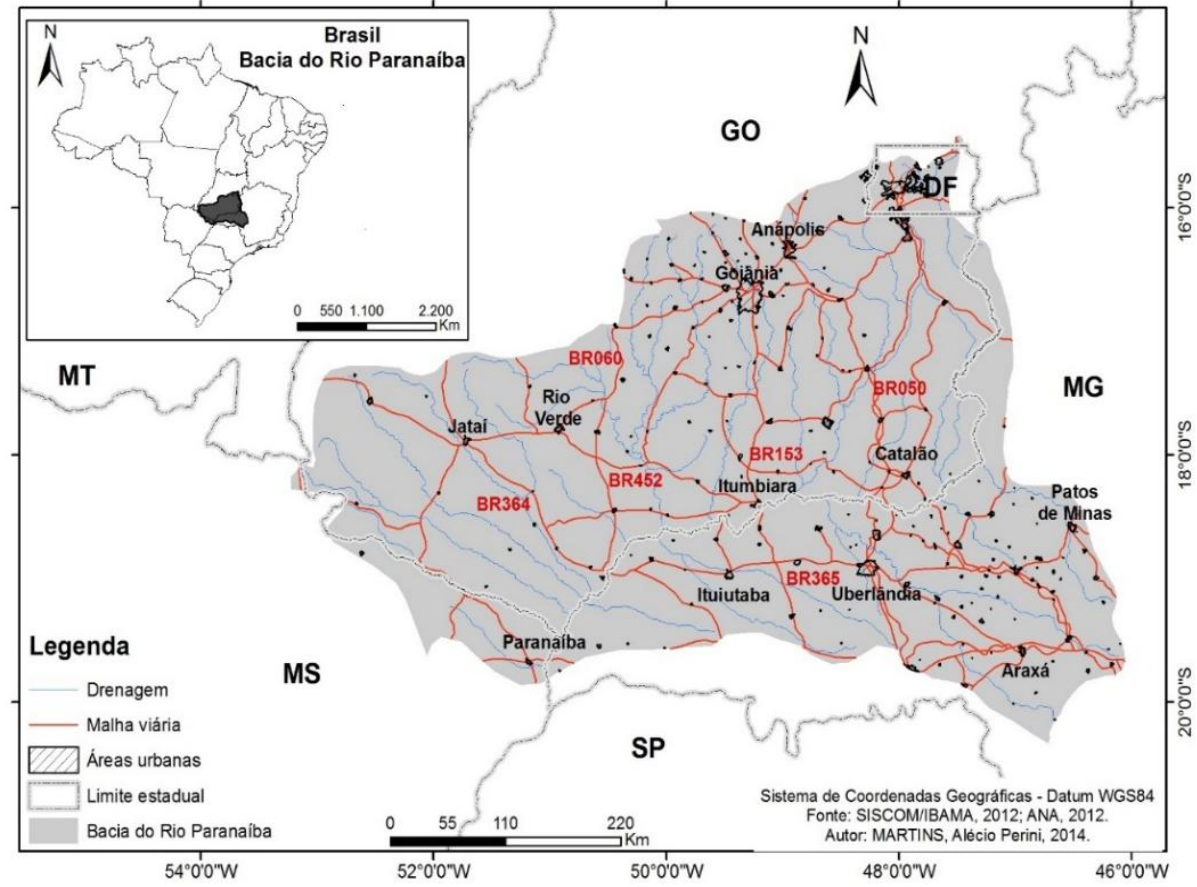

Figura 1 - Localização da área de estudo. Fonte: Agência Nacional de Águas. 2012. Organização: Autores, 2016.

Com base nos estudos de Nimer (1979), destaca-se que a posição da Bacia do Rio Paranaíba na metade do caminho entre as áreas equatoriais e temperadas, faz com que a região seja atingida por perturbações do sul (associadas às Massas Polares), de leste e de oeste (relacionadas com centros de baixa pressão, que recebem o nome de Linhas de Instabilidade Tropical). Estas perturbações de oeste, que ocorrem com maior frequência na primavera e no verão, associam-se à alta umidade amazônica (Massa Equatorial Continental) provocando chuvas na região. Quando associadas às frentes frias que, mesmo no verão, continuam atuando, forma-se um "corredor" entre a região amazônica e o litoral do sudeste conhecido como Zona de Convergência do Atlântico Sul (ZCAS), responsável por precipitações contínuas e intensas na região, por períodos que se estendem de 3 a 7 dias.

A partir do mapeamento elaborado e de informações do Plano de Recursos Hídricos do Rio Paranaíba (ANA, 2013), observa-se uma grande amplitude altimétrica com altitudes variando de $240 \mathrm{~m}$ na confluência do Rio Paranaíba com o Rio Grande até cotas superiores a $1300 \mathrm{~m}$ nas nascentes localizadas no Distrito Federal e nas nascentes do Rio Araguari. As áreas de maior altitude encontram-se na Província Tocantins, cujo embasamento geológico é representado principalmente por grupos e formações muito antigas, compostas por rochas cristalinas, predominantemente metamórficas. 


\section{PROCEDIMENTOS METODOLÓGICOS.}

As estações climatológicas utilizadas nesta caracterização, bem como seu intervalo de dados e localização encontram-se na tabela 1. Foram selecionadas estações automáticas localizadas na área da bacia do Rio Paranaíba e entorno próximo, sendo selecionadas 33 estações, das quais 22 se encontram no interior da área de estudo.

Tabela 1 - Rede de estações automáticas do INMET utilizadas neste estudo.

\begin{tabular}{|c|c|c|c|}
\hline MUNICIPIO & LATITUDE & LONGITUDE & ALTITUDE (m) \\
\hline ÁGUAS EMENDADAS & $-15,5965$ & $-47,6258$ & 1030 \\
\hline ALTO ARAGUAIA* & $-17,3394$ & $-53,2244$ & 753 \\
\hline ALTO TAQUARI* & $-17,8410$ & $-53,2895$ & 862 \\
\hline ARAXÁ & $-19,6057$ & $-46,9496$ & 1018 \\
\hline BRASÍLIA & $-15,7893$ & $-47,9258$ & 1161 \\
\hline CAIAPÔNIA* & $-16,9668$ & $-51,8176$ & 740 \\
\hline CASSILÂNDIA & $-19,1225$ & $-51,7207$ & 495 \\
\hline CATALÃO & $-18,1548$ & $-47,9276$ & 901 \\
\hline CHAPADÃO DO SUL & $-18,8021$ & $-52,6026$ & 821 \\
\hline CIDADE DE GOIÁS* & $-15,9397$ & $-50,1414$ & 513 \\
\hline COSTA RICA* & $-18,4926$ & $-53,1712$ & 727 \\
\hline CRISTALINA & $-16,7849$ & $-47,6130$ & 1211 \\
\hline FORMIGA* & $-20,4549$ & $-45,4538$ & 878 \\
\hline GAMA & $-15,9351$ & $-48,1374$ & 990 \\
\hline GOIANÉSIA* & $-15,2202$ & $-48,9901$ & 667 \\
\hline GOIÂNIA & $-16,6428$ & $-49,2202$ & 727 \\
\hline IPORÁ* & $-16,4231$ & $-51,1488$ & 610 \\
\hline ITUIUTABA & $-18,9529$ & $-49,5251$ & 540 \\
\hline ITUMBIARA & $-18,4098$ & $-49,1921$ & 491 \\
\hline JALES* & $-20,1650$ & $-50,5951$ & 460 \\
\hline JATAÍ & $-17,9236$ & $-51,7175$ & 670 \\
\hline JOÃO PINHEIRO* & $-17,7848$ & $-46,1194$ & 877 \\
\hline LUZIÂNIA & $-16,2605$ & $-47,9670$ & 1001 \\
\hline MORRINHOS & $-17,7451$ & $-49,1017$ & 751 \\
\hline PARANAÍBA & $-19,6955$ & $-51,1818$ & 408 \\
\hline PATROCÍONIO & $-18,9967$ & $-46,9859$ & 978 \\
\hline PIRES DO RIO & $-17,3042$ & $-48,2841$ & 757 \\
\hline RIO VERDE & $-17,7853$ & $-50,9649$ & 780 \\
\hline SACRAMENTO & $-19,8753$ & $-47,4341$ & 913 \\
\hline SÃO SIMÃO & $-18,969142$ & $-50,633449$ & 492 \\
\hline SILVÂNIA & $-16,6798$ & $-48,6182$ & 952 \\
\hline UBERLÂNDIA & $-18,9171$ & $-48,2557$ & 875 \\
\hline UNAÍ* & $-16,5541$ & $-46,8819$ & 641 \\
\hline
\end{tabular}

* Estações localizadas fora da bacia do Rio Paranaíba, utilizadas para interpolação.

Fonte: Instituto Nacional de Meteorologia - INMET, 2018. Organização: Autores, 2018.

Na área da bacia do Rio Paranaíba, assim como acontece em grande parte do Brasil Central, existe uma deficiência na cobertura e distribuição espacial de estações climatológicas com séries históricas (Figura 2). Apesar de permitir uma análise geral do clima regional, estas estações não permitem estudos mais específicos de distribuição espacial dos fenômenos, pois a maioria das estações estão distantes mais de $100 \mathrm{~km}$ uma da outra. Nesse sentido, as imagens de sensoriamento remoto e as ferramentas de geoprocessamento têm 
se mostrado imprescindíveis, pois permitem o mapeamento de variáveis como precipitação, temperatura de superfície e evapotranspiração real pixel a pixel, cobrindo grandes áreas de difícil acesso ou com escassez de estações de monitoramento.

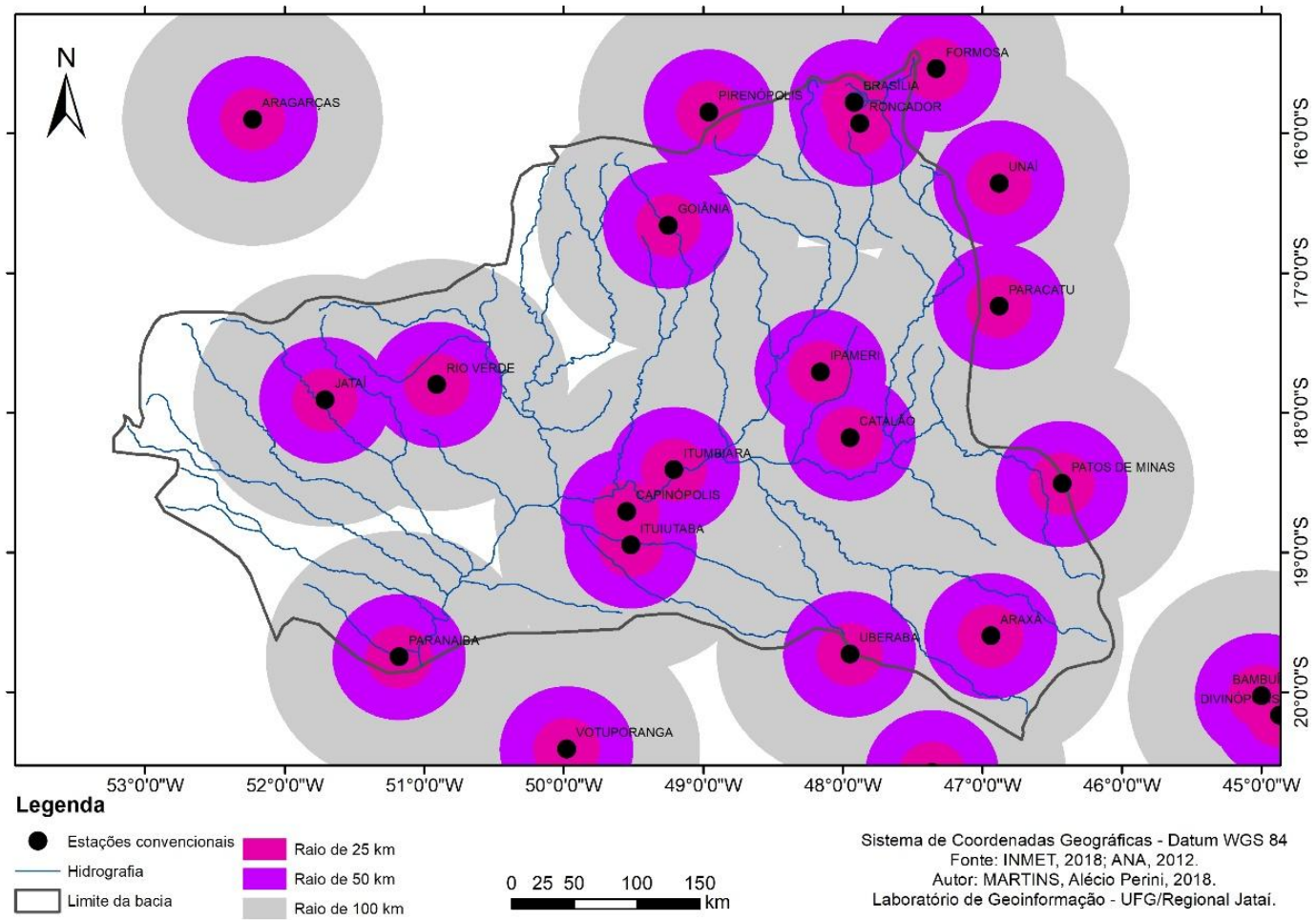

Figura 2 - Estações convencionais do INMET com série histórica de dados. Fonte: Instituto Nacional de meteorologia, 2018. Organização: Autores, 2018.

Já as estações automáticas do INMET apresentam uma cobertura mais eficiente da área (Figura 3), ficando poucas áreas descobertas quando se considera um raio de $100 \mathrm{~km}$, mas se for considerado um raio de $50 \mathrm{~km}$ para análises, estes postos não são suficientes, não permitindo estudos de clima local com maior aprofundamento.

Outra questão importante a ser destacada é que poucas estações apresentam séries de dados superiores a 10 anos, além de falhas significativas nas séries de dados. Para uma melhor gestão do território, sobretudo por se tratar de uma área com intenso uso agropecuário, seria necessário viabilizar a instalação de mais pontos de monitoramento, como por exemplo na região entre as cidades de Rio Verde e Goiânia e na divisa entre os estados de Goiás e Minas Gerais.

Analisando as séries de dados disponibilizadas pelo INMET, assim como a cobertura espacial de estações de monitoramento na área de estudo, optou-se por utilizar as informações disponibilizadas online da rede de estações automáticas, já que o principal objetivo aqui não é analisar o clima local ou regional, mas sim, avaliar os métodos de interpolação e espacialização de dados de temperatura do ar. 


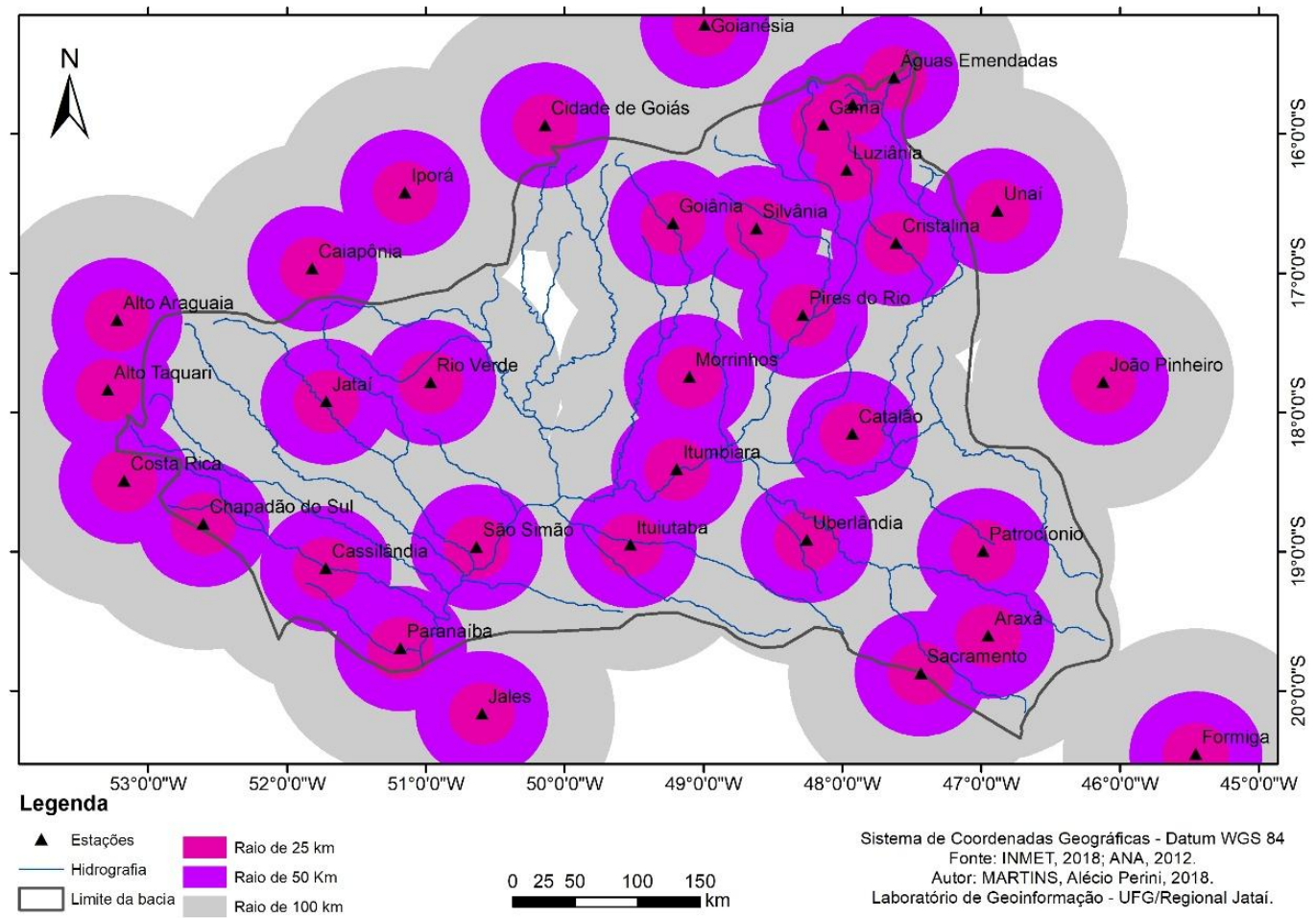

Figura 3 - Estações automáticas do INMET. Fonte: Instituto Nacional de meteorologia, 2018. Organização: Autores, 2018.

Dessa forma, foram realizados testes com seis métodos diferentes, sendo três determinísticos e três geoestatísticos. Os métodos de interpolação mais utilizados para espacialização de dados climatológicos são o inverso do quadrado da distância (IDW) e a Krigagem. Yamamoto e Landim (2013), destacam que o sistema de krigagem baseia-se na ideia de que quanto maior a covariância entre uma amostra e o local que está sendo estimado, mais essa amostra deve contribuir com a estimativa. Dessa forma, considera-se que é um método mais significativo para áreas com maior cobertura de pontos de monitoramento, apresentando estimativas mais confiáveis. Já o IDW é um método puramente geométrico, onde o peso entre as amostras diminui à medida em que essas amostras se distanciam. Enquanto essas distâncias são euclidianas no IDW, na krigagem são baseadas na análise variográfica, que consideram o relacionamento entre os pontos conhecidos e os pontos estimados, fornecendo informações mais detalhadas sobre o agrupamento (YAMAMOTO e LANDIM, 2013). Embora considere apenas as distâncias euclidianas, o IDW tem sido bastante utilizado em interpolações que apresentam poucos pontos de controle, com resultados satisfatórios.

Além do IDW, foram testados mais dois métodos determinísticos para espacialização de dados de temperatura do ar em quatro abordagens distintas: temperatura média do mês de agosto de 2018, temperatura instantânea do ar registrada às 09:00h, às 15:00h e às 21:00h do dia 01 de agosto de 2018 . Estes métodos são o Radial Basis Function (RBF, especificamente o tipo Spline) e o Local Polynomial Interpolation (LPI), que são considerados mais flexíveis que o IDW por permitirem a inserção de outros parâmetros. 
Com os dados de cada estação e, por meio de geração de grade triangular e interpolação de dados, é possível traçar isolinhas que permitem conhecer melhor a distribuição espacial dos elementos do clima. São necessárias informações do entorno para diminuir o efeito de borda provocado pelo processo de interpolação, minimizando a probabilidade de ocorrência de erros.

A etapa de geoprocessamento foi realizada com o uso do software ArcGIS 10.1®, licenciado para o Laboratório de Geoinformação da UFG/Regional Jataí.

As tabelas de dados em formato .xIs foram transformadas em informação espacial (vetor de pontos no formato shapefile) no software ArcGIS 10.1®. Após um tratamento inicial para conversão de Datum e sistema de coordenadas, sendo utilizado Datum WGS84 e sistema de coordenadas geográficas, procedeuse com a interpolação dos dados, em uma escala de base de 1:1.000.000.

A geração de isotermas a partir dessas informações foi feita com o uso da extensão Geostatystical Analyst do software ArcGIS 10.1®. As informações foram espacializadas utilizando métodos determinísticos, em especial o IDW (Inverse Distance Weighting), o Spline (Radial Basis Function - RBF) e o Local Polynomial Interpolation (LPI) e métodos geoestatísticos, especialmente a krigagem e a cokrigagem e o Empirical Bayesian Kriging (EBK). Na cokrigagem foram experimentadas as relações das variáveis temperatura instantânea e temperatura média mensal com dados de altimetria.

Após a interpolação os arquivos foram convertidos para o formato .tif e recortados para os limites da bacia do Rio Paranaíba, passando por processo de reclassificação onde foram definidas 5 classes com intervalos iguais. A avaliação das interpolações foi realizada por meio de validação cruzada, ferramenta também disponível na extensão Geoestatistical Analyst do ArcGIS10.1®. Foram calculados o erro médio absoluto $(E M)$ e a raiz do erro quadrático médio (REQM), metodologia utilizada para avaliar o grau de semelhança entre previsão e observação, conforme disposto por Meira (2010):

$$
\begin{aligned}
& E M=\frac{1}{n} \sum(P e-P o) \\
& R E Q M=\sqrt{\frac{1}{n}} \sum(P e-P o)^{2}
\end{aligned}
$$

Onde Po corresponde à precipitação observada; Pe à precipitação estimada; e n ao número de postos pluviométricos. Os cálculos foram realizados em planilhas eletrônicas do Microsoft Excel 2013®, bem como cálculos de média simples, desvio padrão, variação, regressão e correlação, além da montagem final das tabelas de dados.

Após o tratamento estatístico, foram comparados os valores medidos e os valores estimados em cada uma das 33 estações automáticas, identificando as alterações sofridas pelos dados em cada método de espacialização, as quais foram subdivididas em: Muito Baixo (cor verde), com variação de $\pm 0,5{ }^{\circ} \mathrm{C}$ com relação ao valor registrado na estação; Baixo (cor amarela), com variação de $\pm 1,0{ }^{\circ} \mathrm{C}$; Médio (cor laranja), com variação de $\pm 1,5{ }^{\circ} \mathrm{C}$; Alto (cor vermelha), com variação de $\pm 2,0^{\circ} \mathrm{C}$; e Muito Alto (cor marrom), com variação superior a $\pm 2,0^{\circ} \mathrm{C}$.

Além de tabelas, foram produzidos mapas temáticos para demonstrar o comportamento espacial das variáveis em cada método utilizado por meio do software ArcGIS 10.1®. 


\section{RESULTADOS E DISCUSSÃO}

Na tabela 2 são demonstrados os valores de temperatura média do mês de agosto de 2018 (Coluna TMED) e os respectivos valores de temperatura média preditos pelos três métodos determinísticos de interpolação e espacialização de dados.

Tabela 2 - Dados de temperatura média mensal para o mês de agosto de 2018 mensurados nas estações automáticas do INMET, comparado com os valores preditos pelos métodos determinísticos de espacialização e os respectivos erros

\begin{tabular}{|c|c|c|c|c|c|c|c|c|}
\hline MUNICIPIO & ALT (m) & TMED & IDW & ERRO & RBF & ERRO & LPI & ERRO \\
\hline ÁGUAS EMENDADAS & 1030 & 21,1 & 21,7 & 0,6 & 22,5 & 1,4 & 22,5 & 1,4 \\
\hline ALTO ARAGUAIA & 753 & 23,0 & 21,8 & $-1,1$ & 22,5 & $-0,4$ & 22,7 & $-0,3$ \\
\hline ALTO TAQUARI & 862 & 21,8 & 22,8 & 1,0 & 22,7 & 1,0 & 22,7 & 0,9 \\
\hline ARAXÁ & 1018 & 20,5 & 19,9 & $-0,6$ & 20,0 & $-0,5$ & 20,6 & 0,1 \\
\hline BRASÍLIA & 1161 & 21,6 & 21,8 & 0,2 & 21,7 & 0,1 & 22,6 & 1,0 \\
\hline CAIAPÔNIA & 740 & 24,1 & 23,7 & $-0,4$ & 23,6 & $-0,5$ & 24,1 & 0,0 \\
\hline CASSILÂNDIA & 495 & 24,0 & 22,8 & $-1,7$ & 22,8 & $-1,2$ & 22,6 & $-1,4$ \\
\hline CATALÃO & 901 & 25,6 & 22,3 & $-1,4$ & 22,0 & $-3,6$ & 21,9 & $-3,7$ \\
\hline CHAPADÃO DO SUL & 821 & 23,8 & 24,2 & $-1,4$ & 22,7 & $-1,1$ & 22,3 & $-1,5$ \\
\hline CIDADE DE GOIÁS & 513 & 27,2 & 22,4 & $-6,5$ & 24,3 & $-2,9$ & 24,6 & $-2,6$ \\
\hline COSTA RICA & 727 & 22,1 & 22,9 & 0,8 & 22,9 & 0,8 & 22,4 & 0,3 \\
\hline CRISTALINA & 1211 & 21,0 & 22,8 & 1,8 & 23,1 & 2,1 & 22,7 & 1,7 \\
\hline FORMIGA & 878 & 19,1 & 20,2 & 3,7 & 21,3 & 2,2 & 17,3 & $-1,9$ \\
\hline GAMA & 990 & 21,9 & 21,8 & $-0,1$ & 22,4 & 0,5 & 22,9 & 1,0 \\
\hline GOIANÉSIA & 667 & 25,5 & 22,7 & $-2,8$ & 26,6 & 1,1 & 23,7 & $-1,8$ \\
\hline GOIÂNIA & 727 & 23,9 & 22,6 & $-1,3$ & 23,5 & $-0,4$ & 23,8 & $-0,1$ \\
\hline IPORÁ & 610 & 25,1 & 24,5 & $-0,6$ & 24,6 & $-0,6$ & 25,1 & 0,0 \\
\hline ITUIUTABA & 540 & 22,6 & 23,2 & 0,6 & 22,8 & 0,2 & 22,8 & 0,2 \\
\hline ITUMBIARA & 491 & 23,4 & 22,5 & $-0,9$ & 22,6 & $-0,8$ & 22,9 & $-0,5$ \\
\hline JALES & 460 & 21,8 & 22,6 & 0,8 & 22,6 & 0,8 & 22,6 & 0,8 \\
\hline JATAÍ & 670 & 22,2 & 23,1 & 0,9 & 23,3 & 1,1 & 23,5 & 1,3 \\
\hline JOÃO PINHEIRO & 877 & 21,9 & 22,0 & 0,1 & 21,9 & 0,0 & 21,1 & $-0,8$ \\
\hline LUZIÂNIA & 1001 & 22,8 & 21,8 & $-1,0$ & 21,7 & $-1,1$ & 22,6 & $-0,3$ \\
\hline MORRINHOS & 751 & 22,1 & 23,3 & 1,2 & 23,5 & 1,4 & 23,5 & 1,4 \\
\hline PARANAÍBA & 408 & 22,5 & 22,8 & 0,3 & 22,9 & 0,4 & 22,7 & 0,2 \\
\hline PATROCÍONIO & 978 & 19,2 & 20,8 & 1,6 & 21,6 & 2,4 & 21,7 & 2,5 \\
\hline PIRES DO RIO & 757 & 23,0 & 22,6 & $-0,4$ & 22,7 & $-0,3$ & 22,9 & $-0,1$ \\
\hline RIO VERDE & 780 & 22,5 & 22,8 & 0,3 & 23,3 & 0,8 & 23,7 & 1,2 \\
\hline SACRAMENTO & 913 & 20,3 & 20,7 & 0,4 & 21,0 & 0,7 & 20,9 & 0,6 \\
\hline SÃO SIMÃO & 492 & 23,0 & 22,7 & $-0,3$ & 22,7 & $-0,3$ & 22,9 & $-0,1$ \\
\hline SILVÂNIA & 952 & 22,2 & 23,1 & 0,9 & 23,2 & 1,0 & 23,4 & 1,2 \\
\hline UBERLÂNDIA & 875 & 22,5 & 23,2 & 0,7 & 22,7 & 0,2 & 22,3 & $-0,2$ \\
\hline UNAÍ & 641 & 23,8 & 21,5 & $-2,3$ & 21,8 & $-2,0$ & 20,9 & $-2,9$ \\
\hline MEDIA & & 22,6 & 22,4 & $-0,2$ & 22,7 & 0,1 & 22,5 & $-0,1$ \\
\hline DESVIO PADRÃO & & 1,729 & 1,039 & 1,681 & 1,155 & 1,313 & 1,380 & 1,378 \\
\hline VARIAÇÃO & & 2,988 & 1,080 & 2,825 & 1,334 & 1,725 & 1,903 & 1,898 \\
\hline CORRELAÇÃO & & & 0,561 & $-0,826$ & 0,650 & $-0,744$ & 0,628 & $-0,626$ \\
\hline R2 & & & 0,315 & 0,682 & 0,423 & 0,554 & 0,394 & 0,392 \\
\hline
\end{tabular}

ALT: altitude; TMED: temperatura média; IDW: inverso do quadrado da distância; ERRO: erro médio; RBF: Radial Basis Function; LPI: Local Polynomial Interpolation.

Fonte: Instituto Nacional de Meteorologia - INMET, 2018. Organização: Autores, 2018. 
As células destacadas pela cor verde indicam as estações e métodos onde os dados espacializados apresentaram erro médio igual ou inferior a 0,5 ${ }^{\circ} \mathrm{C}$, tanto para mais (superestimação) quanto para menos (subestimação). Neste estudo, foi considerado o valor como muito baixo, pois, ao se tratar de médias, não causam grandes interferências na aplicação destas informações em outros estudos. Os valores classificados como "baixo" aparecem na cor amarela, com erro médio igual ou inferior a $1,0^{\circ} \mathrm{C}$, para mais ou para menos. Apesar de serem erros significativos para informações de temperatura do ar, ainda podem ser utilizados para conhecimento da distribuição espacial da variável na região da Bacia do Rio Paranaíba.

Já os valores que aparecem nas tonalidades de laranja, vermelho e marrom apresentam erros superiores a $1,0{ }^{\circ} \mathrm{C}$, comprometendo estudos mais específicos que necessitem de dados climáticos para regiões sem postos de monitoramento.

Considerando os métodos analisados, para temperatura média, o IDW apresentou 21 estações com erro de até 1,0 ㅇ, o RBF, 20 estações, e o LPI, 19 estações. Porém, se considerarmos o resultado final da espacialização, o LPI apresenta formas mais suavizadas das isotermas, demonstrando coerência com outras informações sobre a bacia hidrográfica como altitude e formas de relevo.

Outra questão importante a se destacar é que as estações que apresentaram maiores erros estão localizadas no entorno da bacia (Figuras 4 e 5) e foram utilizadas para completar o processo de interpolação (Cidade de Goiás, Formiga, Goianésia e Unaí). A falta de continuidade com áreas adjacentes pode ser um dos fatores que explicam os erros mais altos, indicando a importância de se utilizar pontos externos à área de interesse para realizar a interpolação.

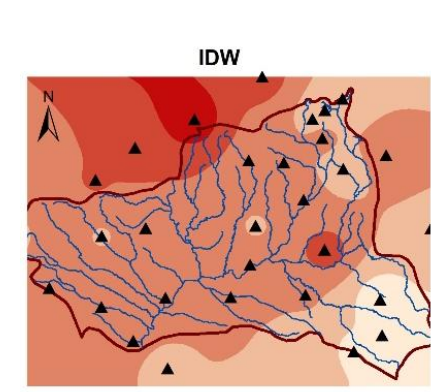

Métodos determinísticos
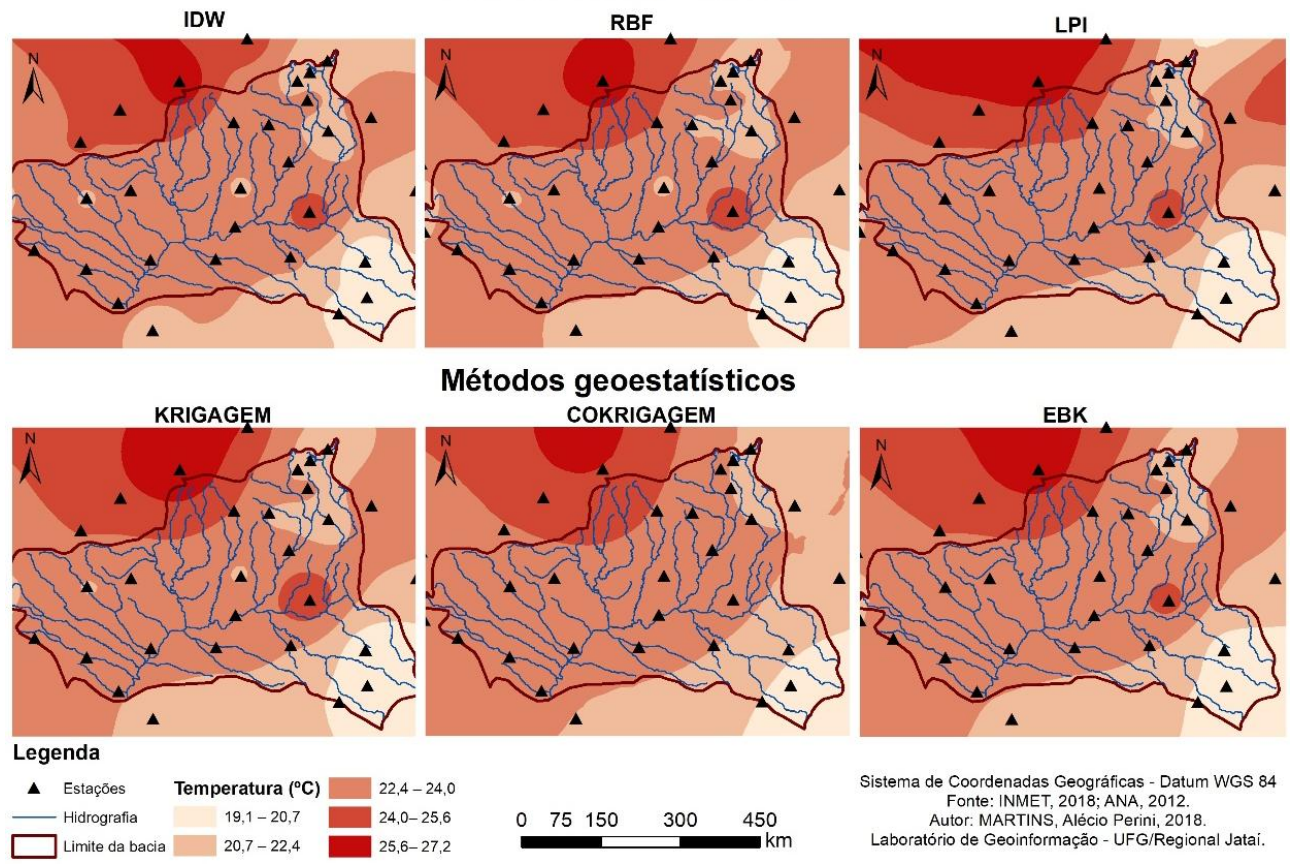

Métodos geoestatísticos
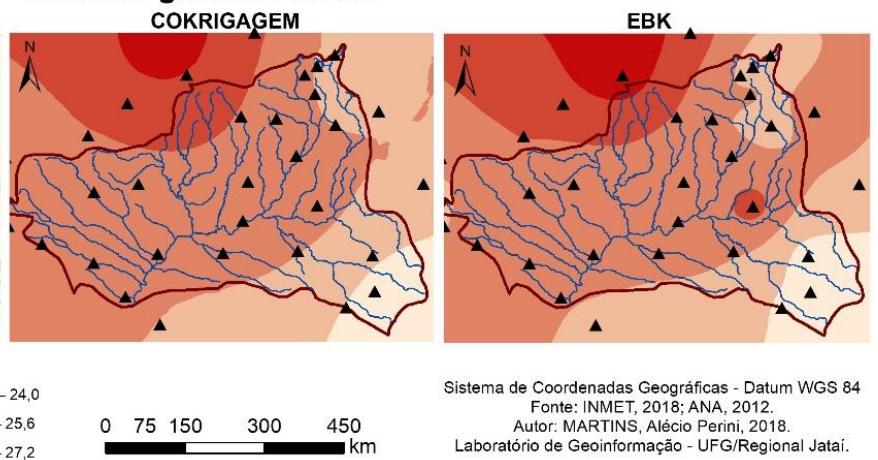

Figura 4 - Comparação do resultado visual da espacialização da temperatura média mensal nos seis métodos analisados. Fonte: Instituto Nacional de meteorologia, 2018. Organização: Autores, 2018. 
Com relação ao Erro Médio calculado, os três métodos subestimaram as informações de temperatura média apresentando valores de $-0,2321,-0,0168$ e -0,0722 para o IDW, RBF e LPI, respectivamente. Os valores de erro quadrático médio correspondente foram de 1,2985, 1,3215 e 1,3599. O erro quadrático médio é o que vai apresentar a precisão do método por ser mais sensível a erros. O valor será sempre positivo e, quanto mais próximo de zero, mais perfeita será a previsão.

Por esse parâmetro e para as condições apresentadas na área de estudo, percebe-se que o IDW foi o que mais se aproximou de zero, indicando maior precisão na previsão de informações para locais onde não existem estações meteorológicas ou postos de monitoramento instalados, embora tenha apresentado o menor valor de correlação quando comparados os valores estimados e os valores medidos em cada estação. Considerando as correlações entre valores medidos e preditos (ou estimados), os métodos RBF e LPI apresentam melhores respostas, mas analisando em conjunto as informações de erro quadrático médio, variação e desvio padrão, conclui-se que o IDW, apesar de não apresentar um desenho espacial com isotermas contínuas, é o que menos distorce as informações dos métodos analisados.

Já com relação aos métodos geoestatísticos, foram considerados três tipos de krigagem: a Krigagem ordinária, a CoKrigagem (inserindo a variável de altimetria) e o EBK (Empirical Bayesian Kriging). Conforme observado na tabela 3, estes métodos apresentaram quantidades semelhantes de estações com erro inferior a $1,0^{\circ} \mathrm{C}$, sendo 19 estações para a krigagem, 20 para a CoKrigagem e 21 para o EBK, sendo que estes dois últimos apresentaram menores desvio padrão e variação e maior correlação com os dados mensurados nas estações. Isso demonstra a interdependência entre valores de temperatura do ar e altimetria, já comprovado em diversas literaturas e estudos topoclimáticos.

Com relação ao erro médio, os métodos apresentaram valores de 0,0431, 0,0104 e -0,0496 para Krigagem Ordinária, CoKrigagem e EBK, respectivamente, e erros quadráticos médios de 1,3210, 1,0102 e 1,2804. Estes valores deixam claro que, para a variável de temperatura do ar, o método da CoKrigagem, considerando a altimetria como variável secundária, é o mais adequado para esta espacialização, demonstrando maior confiabilidade dos dados preditos para áreas que não apresentam estações de monitoramento.

Avaliando a espacialização comparativa demonstrada nas figuras 4 e 5 , considera-se que a CoKrigagem apresenta uma maior coerência espacial considerando as características altimétricas e geomorfológicas da bacia, com menores médias registradas na região do Distrito Federal e nas proximidades da Serra da Canastra e nascentes do Rio Paranaíba, onde as altitudes médias ficam próximas a 1000 metros. As temperaturas aumentam em direção ao norte e noroeste, rumo ao Norte/Noroeste de Goiás, depressão do Araguaia e estado do Mato Grosso. Se comparada aos métodos determinísticos, a CoKrigagem se mostra mais eficiente que o IDW tanto na predição de erros quanto no resultado visual do processo de espacialização, sendo o método mais indicado para espacialização da temperatura do ar.

O gráfico da figura 6 corrobora com esta discussão, ao apresentar a CoKrigagem como superior, comparada à quantidade de estações com erro inferior a $1,0^{\circ} \mathrm{C}$ demonstrada pelos outros métodos. Destaca-se ainda a eficácia 
do EBK, método que apresentou o segundo menor erro quadrático médio entre os seis analisados.

Tabela 3 - Dados de temperatura média mensal para o mês de agosto de 2018 mensurados nas estações automáticas do INMET, comparado com os valores preditos pelos métodos geoestatísticos de espacialização e os respectivos erros

\begin{tabular}{|c|c|c|c|c|c|c|c|c|}
\hline MUNICIPIO & ALT $(m)$ & TMED & KRIG. & ERRO & COKRIG. & ERRO & EBK & ERRO \\
\hline ÁGUAS EMENDADAS & 1030 & 21,1 & 22,2 & 1,1 & 22,4 & 1,3 & 22,4 & 1,4 \\
\hline ALTO ARAGUAIA & 753 & 23,0 & 22,4 & $-0,6$ & 22,5 & $-0,4$ & 22,6 & $-0,4$ \\
\hline ALTO TAQUARI & 862 & 21,8 & 22,6 & 0,9 & 22,8 & 1,1 & 22,7 & 0,9 \\
\hline ARAXÁ & 1018 & 20,5 & 16,9 & $-3,6$ & 20,0 & $-0,5$ & 19,9 & $-0,6$ \\
\hline BRASÍLIA & 1161 & 21,6 & 21,7 & 0,1 & 22,3 & 0,7 & 22,0 & 0,4 \\
\hline CAIAPÔNIA & 740 & 24,1 & 23,5 & $-0,6$ & 23,6 & $-0,6$ & 23,6 & $-0,5$ \\
\hline CASSILÂNDIA & 495 & 24,0 & 22,9 & $-1,1$ & 22,7 & $-1,3$ & 22,8 & $-1,2$ \\
\hline CATALÃO & 901 & 25,6 & 22,0 & $-3,6$ & 21,8 & $-3,8$ & 22,0 & $-3,6$ \\
\hline CHAPADÃO DO SUL & 821 & 23,8 & 22,7 & $-1,1$ & 22,6 & $-1,2$ & 22,6 & $-1,2$ \\
\hline CIDADE DE GOIÁS & 513 & 27,2 & 24,7 & $-2,5$ & 25,0 & $-2,3$ & 24,6 & $-2,6$ \\
\hline COSTA RICA & 727 & 22,1 & 22,8 & 0,7 & 22,9 & 0,8 & 21,1 & 0,7 \\
\hline CRISTALINA & 1211 & 21,0 & 23,2 & 2,2 & 22,8 & 1,8 & 22,8 & 2,0 \\
\hline FORMIGA & 878 & 19,1 & 21,2 & 2,1 & 21,0 & 1,9 & 23,0 & 1,3 \\
\hline GAMA & 990 & 21,9 & 22,4 & 0,5 & 22,5 & 0,6 & 20,4 & 0,6 \\
\hline GOIANÉSIA & 667 & 25,5 & 23,6 & $-1,9$ & 23,8 & $-1,7$ & 22,5 & $-1,7$ \\
\hline GOIÂNIA & 727 & 23,9 & 23,6 & $-0,3$ & 23,7 & $-0,2$ & 23,8 & $-0,3$ \\
\hline IPORÁ & 610 & 25,1 & 24,9 & $-0,2$ & 25,0 & $-0,1$ & 23,6 & $-0,2$ \\
\hline ITUIUTABA & 540 & 22,6 & 22,9 & 0,3 & 22,7 & 0,1 & 24,9 & 0,2 \\
\hline ITUMBIARA & 491 & 23,4 & 22,6 & $-0,8$ & 22,9 & $-0,5$ & 22,8 & $-0,7$ \\
\hline JALES & 460 & 21,8 & 22,4 & 0,6 & 22,6 & 0,8 & 22,7 & 0,6 \\
\hline JATAÍ & 670 & 22,2 & 23,3 & 1,1 & 23,3 & 1,1 & 22,4 & 1,1 \\
\hline JOÃO PINHEIRO & 877 & 21,9 & 21,9 & 0,0 & 21,6 & $-0,3$ & 23,3 & $-0,4$ \\
\hline LUZIÂNIA & 1001 & 22,8 & 21,6 & $-1,3$ & 22,1 & $-0,7$ & 21,5 & $-1,0$ \\
\hline MORRINHOS & 751 & 22,1 & 23,6 & 1,5 & 23,6 & 1,5 & 21,8 & 1,5 \\
\hline PARANAÍBA & 408 & 22,5 & 22,9 & 0,4 & 23,0 & 0,5 & 23,6 & 0,3 \\
\hline PATROCÍONIO & 978 & 19,2 & 21,7 & 2,5 & 21,7 & 2,5 & 22,8 & 2,5 \\
\hline PIRES DO RIO & 757 & 23,0 & 22,7 & $-0,3$ & 22,9 & $-0,1$ & 21,7 & $-0,2$ \\
\hline RIO VERDE & 780 & 22,5 & 23,2 & 0,7 & 23,5 & 1,0 & 22,8 & 0,8 \\
\hline SACRAMENTO & 913 & 20,3 & 20,9 & 0,6 & 20,7 & 0,4 & 23,3 & 0,5 \\
\hline SÃO SIMÃO & 492 & 23,0 & 22,6 & $-0,4$ & 22,5 & $-0,5$ & 20,8 & $-0,4$ \\
\hline SILVÂNIA & 952 & 22,2 & 23,1 & 0,9 & 23,2 & 0,9 & 22,7 & 0,9 \\
\hline UBERLÂNDIA & 875 & 22,5 & 23,0 & 0,5 & 22,6 & 0,1 & 23,1 & 0,3 \\
\hline UNAÍ & 641 & 23,8 & 21,4 & $-2,4$ & 21,4 & $-2,4$ & 22,8 & $-2,4$ \\
\hline MEDIA & & 22,6 & 22,5 & $-0,1$ & 22,6 & 0,0 & 22,5 & $-0,1$ \\
\hline DESVIO PADRÃO & & 1,729 & 1,341 & 1,467 & 1,055 & 1,316 & 1,067 & 1,299 \\
\hline VARIAÇÃO & & 2,988 & 1,799 & 2,152 & 1,114 & 1,731 & 1,138 & 1,687 \\
\hline CORRELAÇÃO & & & 0,568 & $-0,659$ & 0,650 & $-0,793$ & 0,661 & $-0,788$ \\
\hline $\mathrm{R} 2$ & & & 0,323 & 0,434 & 0,422 & 0,628 & 0,437 & 0,621 \\
\hline
\end{tabular}

ALT: altitude; TMED: temperatura média; IDW: inverso do quadrado da distância; ERRO: erro médio; RBF: Radial Basis Function; LPI: Local Polynomial Interpolation. Fonte: Instituto Nacional de Meteorologia - INMET, 2018. Organização: Autores, 2018.

Além das temperaturas mensais, foram realizados testes para espacialização dos dados de temperatura instantânea às 09:00h, 15:00h e 21:00h (horário de Brasília), considerando os horários de realização de leitura nas estações convencionais. Observou-se que, devido a fatores regionais como intensidade de radiação, localização das estações em área urbana, periurbana 
ou rural, direção das vertentes onde os postos estão instalados, altitude, entre outros, apenas a temperatura registrada às 09:00h apresentou uma maior correspondência com o comportamento da média mensal, visto que é o horário com menor influência da radiação. Embora a variação seja maior, com exceção do período noturno, a maioria dos dados estimados apresentam erro igual ou inferior a $0,5^{\circ} \mathrm{C}$ (Figura 7).

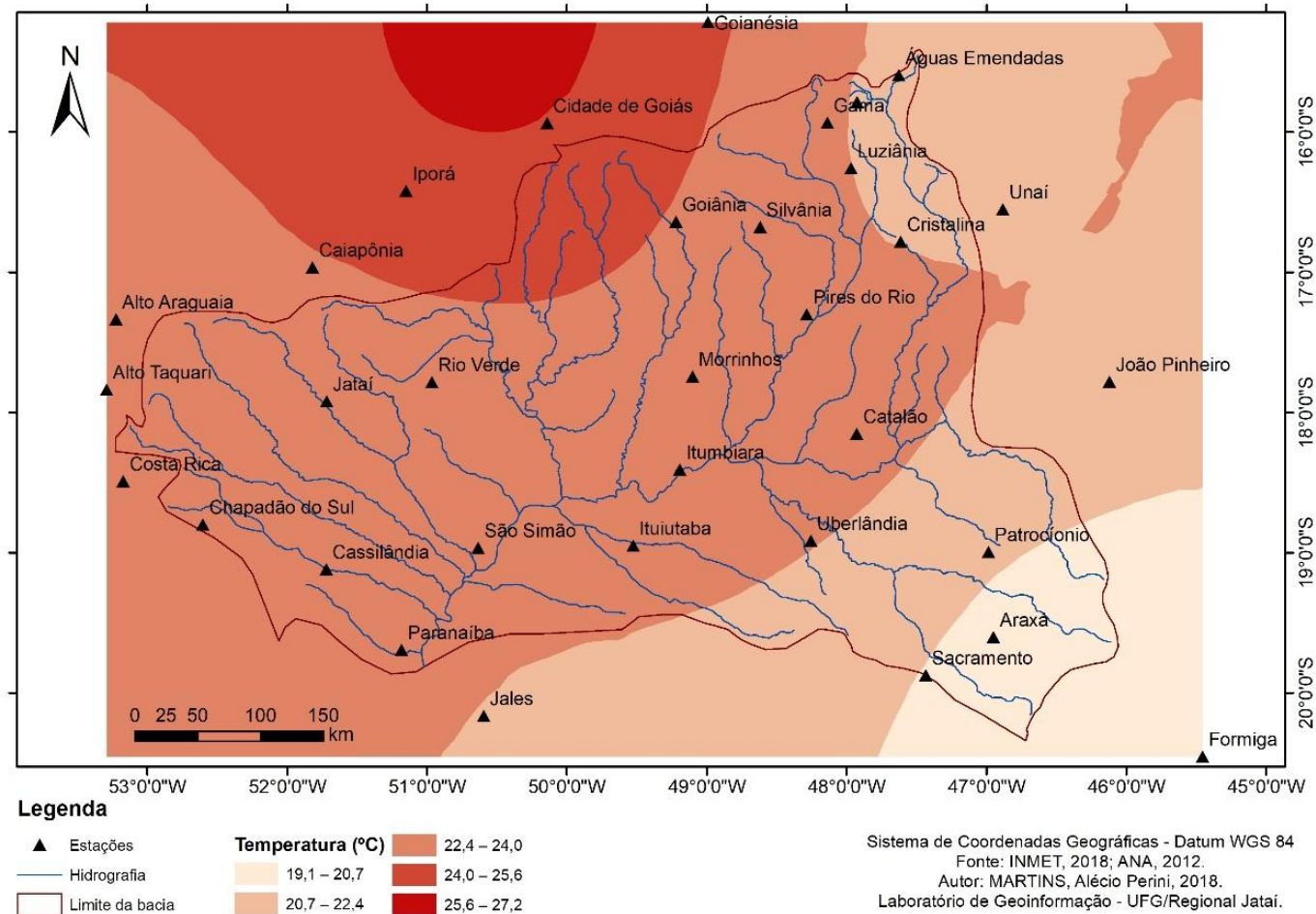

Figura 5 - Espacialização dos dados de temperatura do ar para o mês de agosto de 2018 na Bacia do Rio Paranaíba pelo método da CoKrigagem. Fonte: Instituto Nacional de meteorologia, 2018. Organização: Autores, 2018.

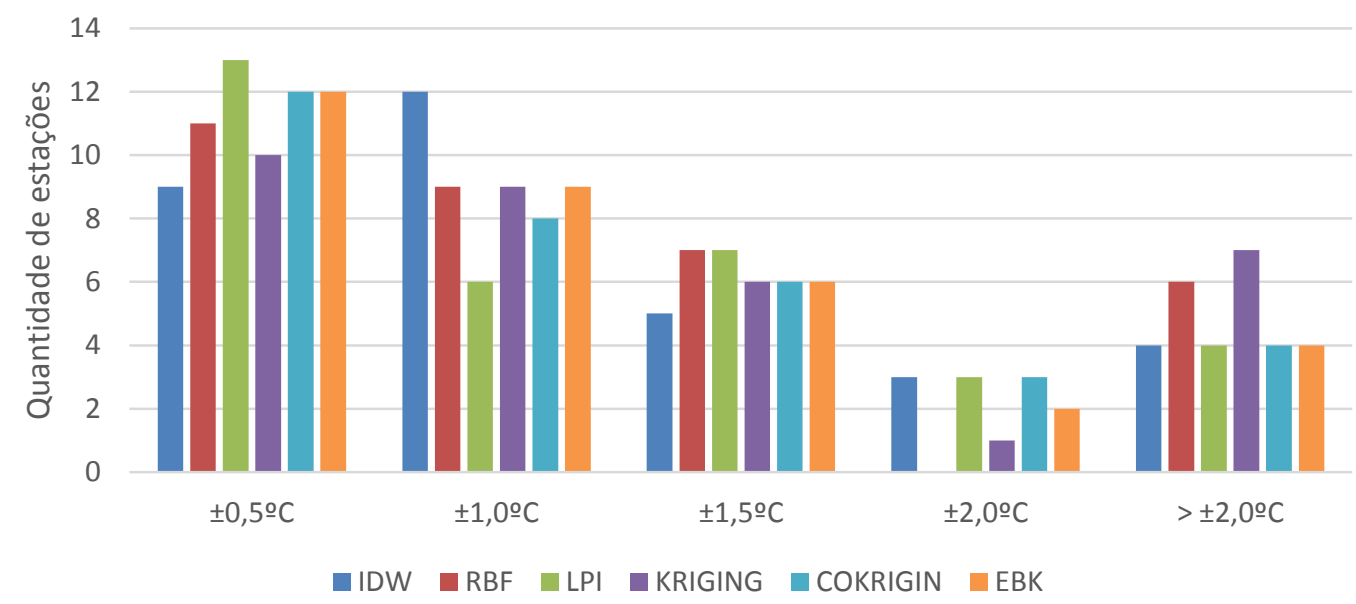

Figura 6 - Comparativo entre a quantidade de estações e o erro bruto apresentado em cada método analisado. Fonte: Instituto Nacional de meteorologia, 2018. Organização: Autores, 2018. 
Considerando os métodos analisados, para temperatura instantânea, o IDW e o RBF apresentaram 17 estações com erro de até $1,0{ }^{\circ} \mathrm{C}$, o LPI 15, a Krigagem ordinária e a CoKrigagem 17 e o EBK 16 estações para as 09:00h, portanto, sem grandes variações. Assim como na análise para temperatura média, o IDW apresentou menores variação e desvio padrão, sendo a maior correlação apresentada pelo LPI entre os métodos determinísticos. Entre os geoestatísticos, a CoKrigagem apresentou os menores valores de desvio padrão e variância e maior correlação em relação aos demais, seguindo a mesma tendência da temperatura média, mas com valores superiores ao IDW.

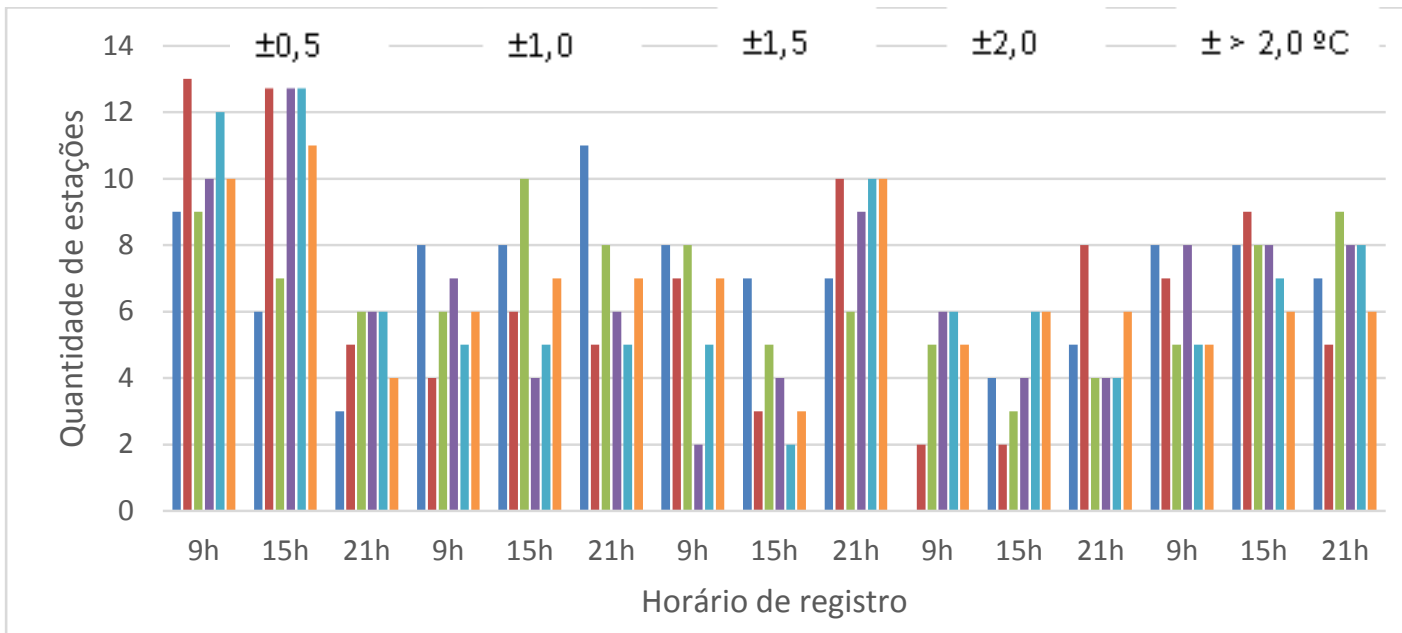

$\square$ IDW $\square$ RBF $\square$ LPI KRIGING $\square$ COKRIGIN $\quad$ EBK

Figura 7 - Comparativo entre a quantidade de estações e o erro bruto apresentado em cada método analisado em três turnos. Fonte: Instituto Nacional de meteorologia, 2018. Organização: Autores, 2018.

Considerando os erros médios, os métodos apresentaram valores de $-0,0773,0,0372,-0,1267,0,0143,0,0203$ e -0,0130 para IDW, RBF, LPI, Krigagem Ordinária, CoKrigagem e EBK, respectivamente. Os erros quadráticos médios calculados foram de 1,5747, 1,5845, 1,5010, 1,6939, 1,5555, 1,5383 para os mesmos métodos. Nota-se que enquanto IDW, LPI e EBK subestimaram os erros, os demais métodos superestimaram. Já os erros quadráticos apresentaram-se muito semelhantes, com exceção da Krigagem Ordinária que não se mostrou adequada para esta espacialização. Neste comparativo, o LPI apresenta as menores possibilidades de estimar temperaturas com erros em locais onde não existem postos de monitoramento.

Se considerarmos o resultado final da espacialização (Figura 8), percebese um resultado muito parecido entre o mapa gerado pelo LPI e a CoKrigagem, considerados aqui como os mais eficazes para a temperatura instantânea às 09:00h, assim como acontece com os valores de temperatura média mensal. Importante ressaltar que foram utilizadas informações registradas no dia 01 de agosto de 2018 que, apesar de condições do tempo atmosférico específicas, apresenta comportamento espacial semelhante aos dados médios mensais.

Já para os dados registrados às $15: 00 \mathrm{~h}$ foram observados maiores valores de variação e desvio padrão para os seis métodos, considerando a maior influência da radiação e demais fatores ambientais nos pontos onde os postos 
encontram-se instalados. Para o IDW, 14 estações apresentaram erro bruto igual ou inferior a 1,0 ${ }^{\circ} \mathrm{C}$, para o RBF, 19 estações, e para o LPI, 17 estações. Entre os geoestatísticos, 17 estações apresentaram valores adequados no método da Krigagem e 18 estações para a CoKrigagem e RBK. A maior correlação entre valores registrados e estimados foi apresentada pela CoKrigagem, seguindo a mesma tendência das variáveis anteriores.

\section{Métodos determinísticos}
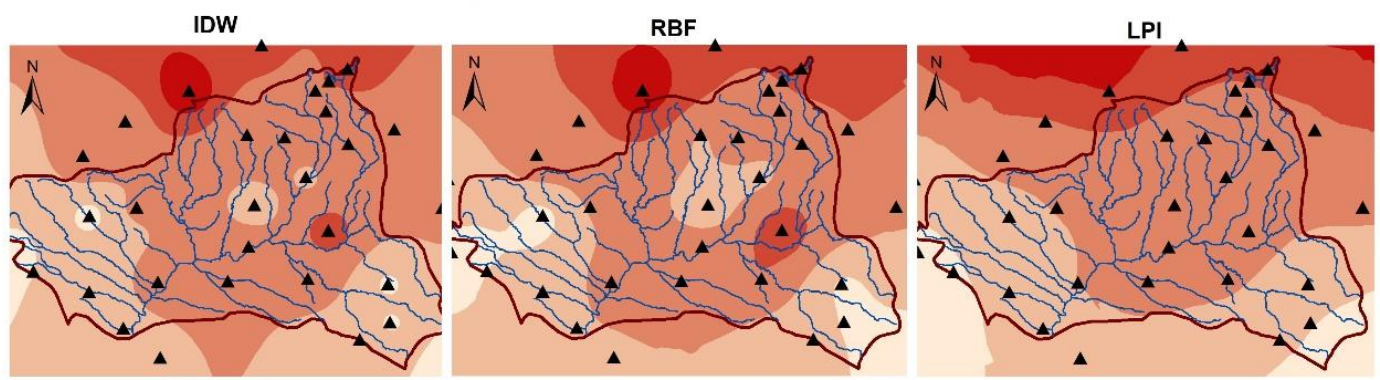

Métodos geoestatísticos
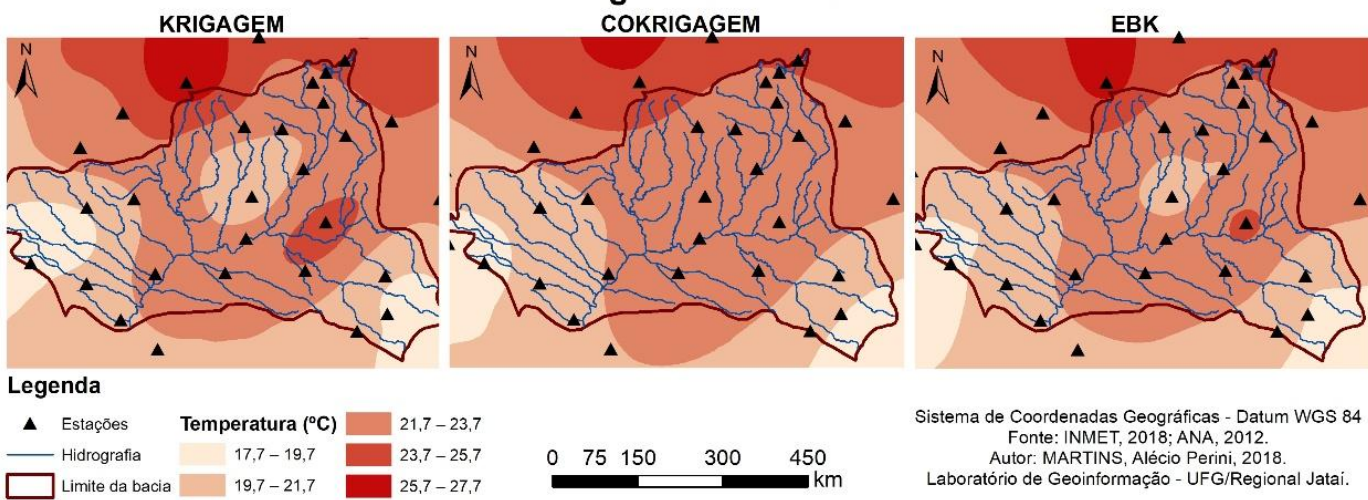

Sistema de Coordenadas Geográficas - Datum WGS 84 Fonte: INMET, 2018; ANA, 2012. Autor: MARTINS, Alécio Perini, 2018. Laboratório de Geoinformação - UFG/Regional Jatai.

Figura 8 - Comparação do resultado visual da espacialização da temperatura instantânea às 09:00h nos seis métodos analisados. Fonte: Instituto Nacional de meteorologia, 2018. Organização: Autores, 2018.

Com relação aos erros apresentados pelas estações às 15:00h para a temperatura instantânea, os métodos apresentaram erros médios de respectivamente $-0,1640,0,0488,-0,3064,-0,0055,0,0383$ e -0,0502 para IDW, RBF, LPI, Krigagem, CoKrigagem e EBK. Apenas RBF e CoKrigagem apresentaram valores superestimados em relação ao registrado nos postos.

Já o erro quadrático médio, que indica o melhor método para espacialização, apresenta valores comparativamente superiores aos de temperatura média e temperatura instantânea às 09:00h, reforçando a influência de fatores ambientais no registro e, consequentemente, na estimativa das temperaturas instantâneas no período vespertino. IDW, RBF e LPI apresentaram erros quadráticos médios de $1,7882,1,8478$ e 1,9203, respectivamente. Já os métodos geoestatísticos apresentaram erros de 1,8978, 1,8211 e 1,8275 para Krigagem, CoKrigagem e EBK. Observa-se que, para este horário, o IDW apresenta menor possibilidade de erro na estimativa, seguido pela CoKrigagem e pelo EBK, embora o desvio padrão e variação do IDW sejam maiores que os registrados nos métodos geoestatísticos.

Avaliando a distribuição espacial da temperatura instantânea às 15:00h nos diferentes métodos (Figura 9), nota-se que o IDW apresenta isotermas 
muito fragmentadas, com pouca continuidade, resultado das deficiências de estimativa do próprio método (embora o erro quadrático médio seja menor). Neste sentido, novamente, a CoKrigagem mostra-se como o método mais adequado para esta espacialização por considerar a variação da altitude, que exerce papel fundamental sobre a distribuição espacial da temperatura do ar.

\section{Métodos determinísticos}

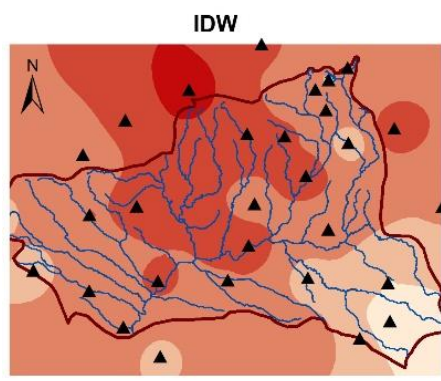

RBF
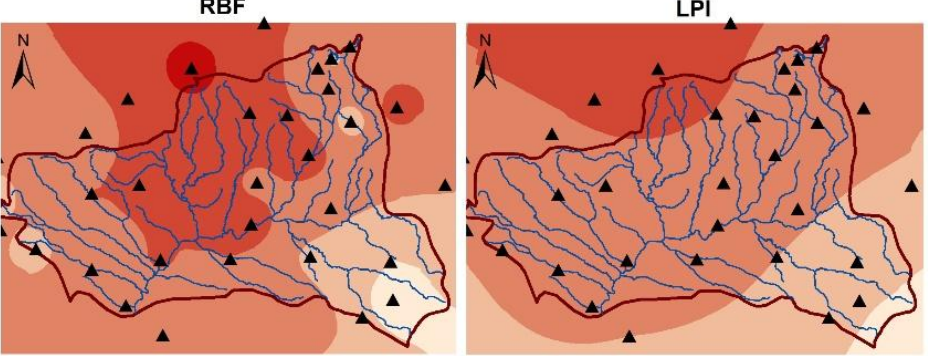

Métodos geoestatísticos

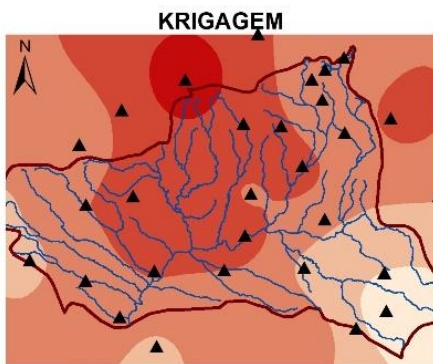
COKRIGAGEM
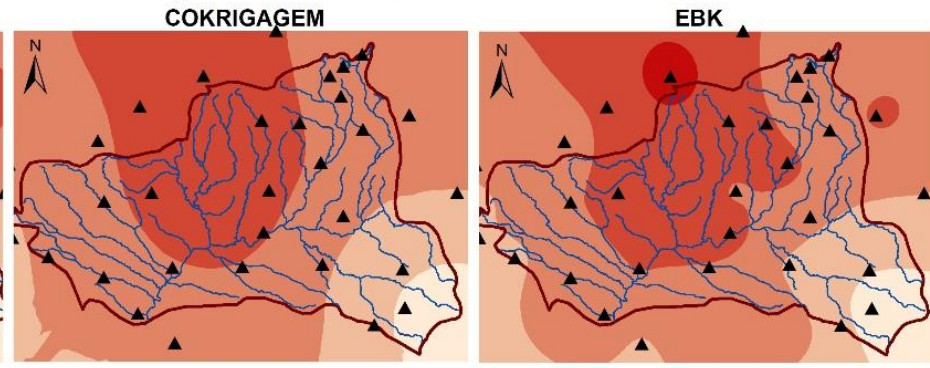

\section{Legenda}

\ Estaçōes Temperatura $\left({ }^{\circ} \mathrm{C}\right) \square 28,14-30,46$

Hidrografia $\quad 23,5-25,82 \square$
$\square$

$\begin{array}{llll}0 & 75 & 150 \quad 300 \quad 450 \\ \mathbf{k m}\end{array}$

Sistema de Coordenadas Geográficas - Datum WGS 84 Fonte: INMET, 2018; ANA, 2012. Autor: MARTINS, Alécio Perini, 2018. Laboratório de Geoinformação - UFG/Regional Jatai.

Figura 9 - Comparação do resultado visual da espacialização da temperatura instantânea às 15:00h nos seis métodos analisados. Fonte: Instituto Nacional de meteorologia, 2018. Organização: Autores, 2018.

De todas as análises realizadas, a temperatura instantânea das 21:00h foi a que apresentou valores mais significativos de variação e menores correlações entre dados registrados e estimados. Este fator é atribuído, principalmente, ao processo desigual de resfriamento da superfície, extremamente dependente das condições ambientais e do microclima da área onde o posto encontra-se instalado, não sendo, portanto, uma variável indicada para análise climática em escalas local e regional.

Conforme o gráfico da figura 7, 14 estações apresentaram erro bruto inferior a $1,0^{\circ} \mathrm{C}$ nos métodos IDW e LPI e 10 no RBF. Quanto aos métodos geoestatísticos, 12 estações apresentaram erros inferiores a $1,0{ }^{\circ} \mathrm{C}$ para a Krigagem e 11 estações na CoKrigagem e RBK. Os menores valores de desvio padrão e variância foram registrados, respectivamente, nos métodos CoKrigagem e RBK, seguindo a mesma tendência das variáveis anteriores. A maior correlação entre dados registrados e estimados foi apresentada pelo IDW.

Analisando os erros médios apresentados por cada método, IDW, RBF e LPI apresentaram, respectivamente, -0,1029, 0,0151 e -0,1797. Nota-se que o RBF, especificamente o Spline, foi o único método determinístico que superestimou todos os valores de temperatura instantânea. Já entre os geoestatísticos, Krigagem, Cokrigagem e EBK apresentaram valores de erro 
médio de 0,0147, 0,0569 e -0,0034, sendo que apenas o último subestimou as informações.

Com relação ao erro quadrático médio, todos os métodos apresentaram valores altos, sobretudo os geoestatísticos. Os métodos IDW, RBF e LPI apresentaram valores de 1,6892, 1,7241 e 1,8038 respectivamente. Krigagem, CoKrigagem e EBK demonstraram erros quadráticos médios de 1,8080, 1,7939 e 1,7482. Novamente, o IDW mostra-se como o método que melhor estima os valores de temperatura instantânea, mas que apresenta muita descontinuidade entre as isotermas geradas na espacialização, intrínsecas às deficiências do método (figura 10).

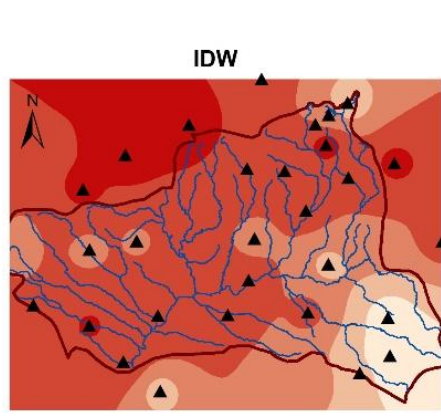

\section{Métodos determinísticos}
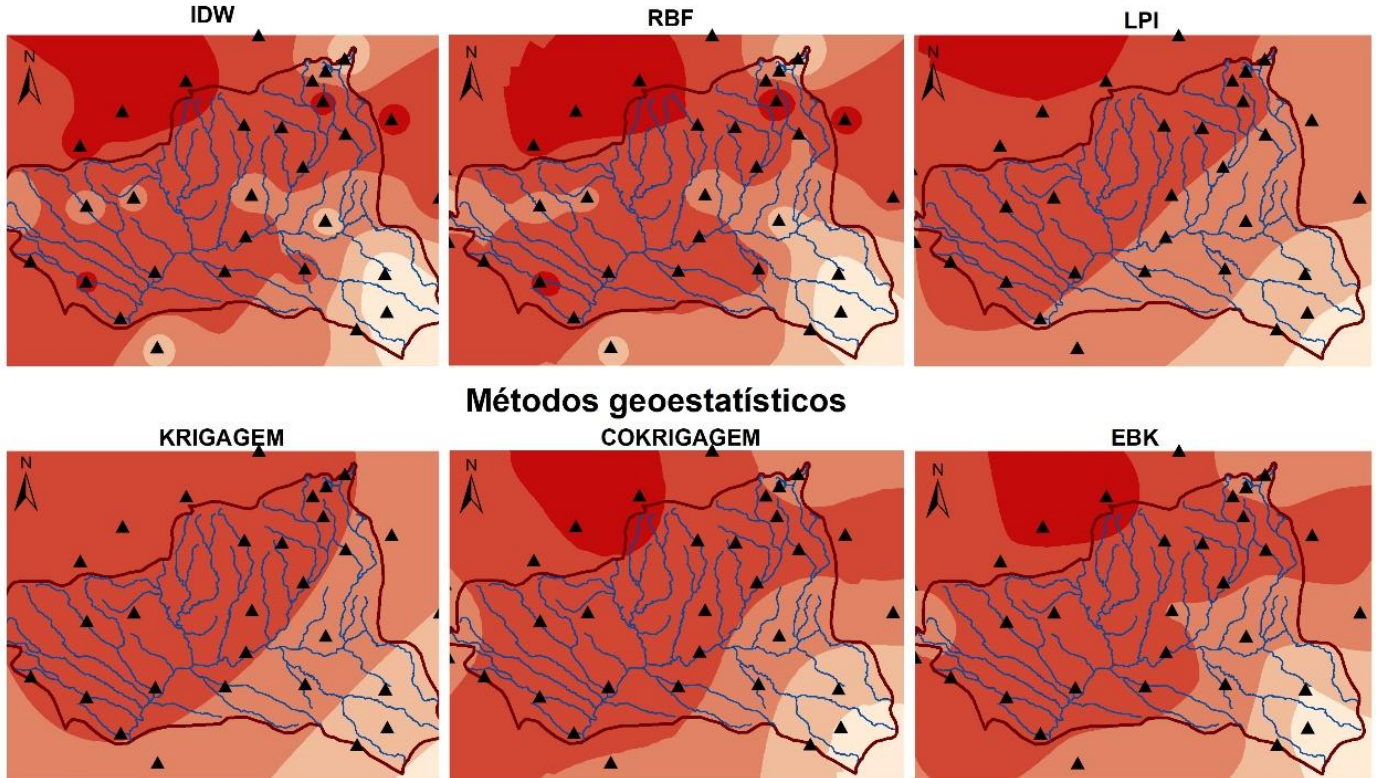

Métodos geoestatísticos
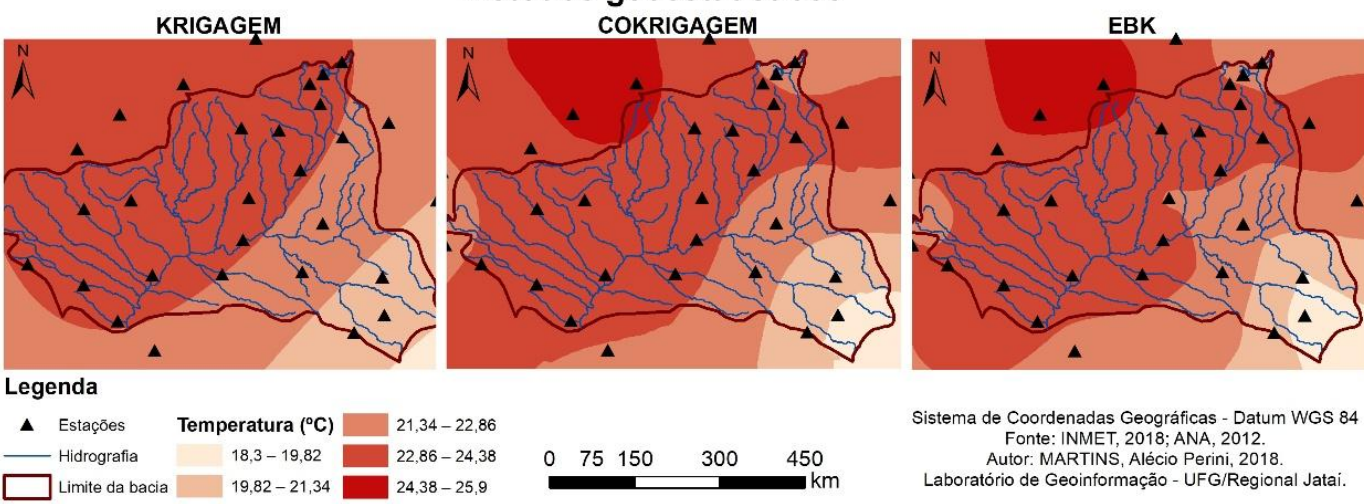

Laboratório de Geoinformação - UFG/Regional Jatai.

Figura 10 - Comparação do resultado visual da espacialização da temperatura instantânea às $21: 00 \mathrm{~h}$ nos seis métodos analisados. Fonte: Instituto Nacional de meteorologia, 2018. Organização: Autores, 2018.

Ao realizar a análise da figura 10 nota-se que, assim como nas análises anteriores, a CoKrigagem apresenta isotermas contínuas, sem a presença de "ruídos" ocasionados pela distância entre as estações, como acontece no IDW. Apesar de demonstrar erro de predição superior aos métodos determinísticos, considera-se que o resultado da espacialização deste método é mais coerente, considerando as características da área de estudo. Em média, o horário das 21:00h apresentou erros médios superiores a $1,5^{\circ} \mathrm{C}$, com o menor $\mathrm{R} 2$ calculado em todas as variáveis analisadas.

\section{CONCLUSÕES}

A partir das experimentações realizadas, conclui-se que o método da CoKrigagem é o mais adequado para espacialização de dados de temperatura do ar, sobretudo ao utilizar a variável altimetria como secundária no processo de 
interpolação. Esta constatação é possível analisando resultados de funções estatísticas como variação, desvio padrão, correlação, regressão, erro médio e, principalmente, erro quadrático médio. Considerando esta última função, quanto mais próximo de 0 o erro apresentado, melhor o comportamento do método na estimativa de valores. Também foram realizados testes de CoKrigagem com a direção das vertentes, mas obteve-se erros significativos nas análises horárias considerando a variação da insolação.

Quanto maior o número de postos de monitoramento, melhores serão os resultados obtidos pelos processos de interpolação e espacialização de dados climatológicos, sobretudo os métodos geoestatísticos. Para áreas com baixa densidade de postos de monitoramento, os métodos determinísticos apresentam menores erros de estimativa, sendo mais recomendados, embora as isolinhas resultantes do processo de espacialização não demonstrem continuidade e formem muitos "ruídos", devido aos erros intrínsecos destes métodos, sobretudo do IDW.

As melhores respostas para a espacialização foram obtidas para a temperatura do ar média mensal, visto que as temperaturas instantâneas apresentam grande interdependência com fatores ambientais como intensidade da radiação, direção da vertente onde a estação se localiza, altitude e microclima do entorno (localização da estação em áreas urbanas, rurais, com vegetação conservada, etc). Sugere-se a realização de novos estudos para temperaturas do ar instantâneas, utilizando estas variáveis no método da Cokgrigagem, que admite a inserção de até três variáveis secundárias.

\section{AGRADECIMENTO}

Agradecemos ao Conselho Nacional de Desenvolvimento Científico e Tecnológico (CNPq) pela concessão de auxílio financeiro ao projeto "Estudo comparativo entre valores de temperatura do ar registrados em estações meteorológicas automáticas do Instituto Nacional de Meteorologia e valores registrados em imagens termais obtidas por sensoriamento remoto", aprovado na chamada MCTI 25/2015, processo 443431/2015-9.

\section{REFERÊNCIAS BIBLIOGRÁFICAS}

ANA - AGÊNCIA NACIONAL DE ÁGUAS. Plano de recursos hídricos e do enquadramento dos corpos hídricos superficiais da bacia hidrográfica do Rio Paranaíba. Brasília: ANA, 2013. 312 p.

AYOADE, J. O. Introdução à Climatologia para os Trópicos. 10a Ed. Rio de Janeiro: Bertrand do Brasil, 2010.

BDMEP - Banco de Dados Meteorológicos para Ensino e Pesquisa. Disponível em <http://www.inmet.gov.br/projetos/rede/pesquisa/> Acesso em 10 abr. 2014.

CARVALHO, J.R.P. de; ASSAD, E.D. Análise espacial da precipitação pluviométrica no Estado de São Paulo: comparação de métodos de interpolação. Engenharia Agrícola, Jaboticabal-SP, v.25, p.377-384, 2005.

CARVALHO, J.R.P. de; ASSAD, E.D.; PINTO, H.S. Interpoladores geoestatísticos na análise da distribuição espacial da precipitação anual e de sua relação com 
altitude. Pesquisa Agropecuária Brasileira, Brasília-DF, v.47, p.1235 - 1242, 2012.

CHRISTOFOLETTI, A. Modelagem de sistemas ambientais. São Paulo: Edgard Blücher Itda., 2000. 236p.

CUNHA, A. de M. et al. Espacialização da precipitação pluvial por meio de krigagem e cokrigagem. Pesquisa agropecuária brasileira, Brasília-DF, v.48, n.09, p. 1179-1191, set. 2013.

ESRI - Environmental Systems Research Institute Inc. ArcGis versão 10.1. EUA: Environmental Systems Research Institute, 2008.

FRANCO, A. C. L.; UDA, P. K. Comparação de métodos de espacialização da precipitação na bacia do Alto Rio Negro, Santa Catarina. In: SIMPÓSIO BRASILEIRO DE SENSORIAMENTO REMOTO - SBSR, 17, 25 a 29 de abril de 2015, João Pessoa-PB. Anais... João Pessoa-PB:INPE, 2015. p. 3052-3058.

GARDIMAN JUNIOR, B. S. et al. Análise de técnicas de interpolação para espacialização da precipitação pluvial na bacia do rio Itapemirim (ES). Revista Ambiência, Guarapuava-PR, v. 8, n.1 p. 61- 71, 2012.

GOOVAERTS, P. Geostatistical approaches for incorporating elevation into the spatial interpolation of rainfall. Journal of Hydrology, v.228, p.113-129, 2000.

MELLO, C.R. de; SILVA, A.M. da. Modelagem estatística da precipitação mensal e anual e no período seco para o Estado de Minas Gerais. Revista Brasileira de Engenharia Agrícola e Ambiental, Campina Grande-PB, v.13, p.68-74, 2009.

NIMER, E. Climatologia do Brasil. Rio de Janeiro: IBGE, 1979.

SILVA, K. R. et al. Interpolação Espacial da Precipitação no Estado do Espírito Santo. Floresta e Ambiente, Seropédica-RJ, v.18, n.04, p.417-427, 2011.

VIOLA, M.R. et al. Métodos de interpolação espacial para o mapeamento da precipitação pluvial. Revista Brasileira de Engenharia Agrícola e Ambiental, Campina Grande-PB, v.14, p.970-978, 2010.

YAMAMOTO, J. K.; LANDIM, P. M. M. Geoestatística - conceitos e aplicações. São Paulo: Oficina de textos, 2013. 215p.. 